\title{
Who is food-insecure in California? Findings from the California Women's Health Survey, 2004
}

\author{
Lucia Kaiser ${ }^{1, *}$, Nikki Baumrind ${ }^{2}$ and Sheila Dumbauld ${ }^{3}$ \\ 'Department of Nutrition, University of California - Davis, One Shields Avenue, Davis, CA 95616, USA: \\ ${ }^{2}$ California Center for Public Health Advocacy, PO Box 2309, Davis, CA 95617, USA: ${ }^{3}$ Independent \\ Research Consultant, 26611 Via Cuervo, Mission Viejo, CA 92691, USA
}

Submitted 28 February 2006: Accepted 5 September 2006: First published online 5 March 2007

\begin{abstract}
Objective: To identify factors associated with food insecurity in California women. Design: The California Women's Health Survey is an ongoing annual telephone survey that collects data about health-related attitudes and behaviours from a randomly selected sample of women. Food insecurity of the women was measured by a 6-item subset of the Food Security Module. Statistical procedures included chisquare tests, $t$-tests, logistic regression analysis and analysis of covariance.

Setting: California, USA.

Subjects: Four thousand and thirty-seven women (18 years or older).

Results: Prevalence of food insecurity was $25.7 \%$. After controlling for income, factors associated with greater food insecurity were Hispanic or Black race/ethnicity; less than a 12th grade education; being unmarried; less than 55 years old; being Spanishspeaking; having spent less than half of one's life in the USA; sadness/depression; feeling overwhelmed; poor physical/mental health interfering with activities; and fair to poor general health. Among Food Stamp Program (FSP) participants, 71\% were food-insecure. Among FSP-eligible women who had not applied for the programme, the prevalence of food insecurity was lower among women responding that they did not need food stamps than in women giving other reasons for not applying (23.9\% vs. $66.9 \%, P<0.001$ ). Factors associated with food insecurity in FSP recipients included being unable to make food stamps last for 30 days, feeling overwhelmed, and having a birthplace in Mexico or Central America.

Conclusions: Along with several socio-economic variables, poor physical and mental health is associated with food insecurity. Whether food insecurity is a cause or effect of poor health remains in question.
\end{abstract}

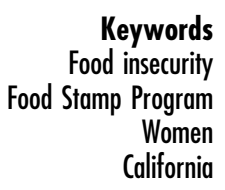

Food security, defined as 'access by all people at all times to enough food for an active healthy life', is one of several conditions that support optimal human health and productivity $^{1,2}$. Households experience food insecurity when food availability or the ability to acquire nutritionally adequate, safe foods in socially acceptable ways is limited or uncertain. When food access becomes severely limited, adults and children in food-insecure households may experience overt hunger, 'the uneasy or painful sensation caused by lack of food'.

In 2004, 13.5 million US households (11.9\% of all households) reported food insecurity at some point during the previous 12 months $^{3}$. In 4.4 million households $(3.9 \%$ of all US households), one or more individuals were hungry at least part of the year because they could not afford enough food. The prevalence of food insecurity is higher than the national average among households with incomes below the poverty level (36.8\%); households with children headed by a single woman (33.0\%) or man
(22.2\%); Black households (29.7\%); and Hispanic households (21.7\%). Households located in central cities and non-metropolitan areas report greater food insecurity than those located in the suburbs and metropolitan areas outside central cities.

Although the prevalence of food insecurity is nearly six times higher in households with incomes below $185 \%$ of the poverty level than in households with incomes above that level, many factors, such as recent divorce, job loss or health problems, contribute to food insecurity and are not captured by the annual income measure ${ }^{4}$. There may also be local factors, such as lack of low-cost housing or transportation, that exacerbate food insecurity ${ }^{5-7}$. Access to wild game, fish and gardens in rural areas increases food security ${ }^{5,8}$. In low-income populations, food and financial life skills are associated with greater food security $^{9,10}$. Food-insecure adults are more likely to report physical and mental health problems, compared with those who are food-secure ${ }^{11-15}$. 
Food assistance programmes provide needy people with access to nutritious foods. However, demonstrating an impact of food assistance programmes on reducing food insecurity can be problematic in cross-sectional studies. A high prevalence of food insecurity and other nutritional problems is often reported among Food Stamp Program (FSP) recipients and may occur because the programme attracts and enrols the neediest households ${ }^{16}$. Appropriate consideration of these selection bias problems is critical in evaluating and interpreting the relationship between food assistance participation and food insecurity.

From 2002 to 2004 in California, the prevalence of food insecurity (12.4\%) exceeded the national average prevalence ${ }^{3}$. One factor in the high prevalence may be the large immigrant population in the state. California is the primary destination for immigrants to the USA, with slightly over half (56\%) coming from Latin America and one-third (33\%) from Asia ${ }^{17}$. In several of California's largest counties, including San Francisco, Los Angeles and Orange County, over $30 \%$ of the population is foreign-born. Low-income immigrant populations report very high levels of food insecurity $^{18}$.

Identifying the subgroups at greatest risk of food insecurity is necessary to target social services efficiently. Given their role in feeding a family, low-income women, especially those in immigrant households, may be particularly vulnerable to food insecurity ${ }^{19}$. In the present study we use data from the 2004 California Women's Health Survey (CWHS) to identify factors associated with food insecurity among women, as determined by a 6-item subset of the Food Security Module (FSM). Since FSP recipients generally report high levels of food insecurity and their well-being is of particular interest to public health and social services programmes, we also examine factors related to greater food insecurity in this subpopulation of women.

\section{Methods}

The CWHS, coordinated by the Survey Research Group, is an ongoing annual telephone survey that collects data about health-related attitudes and behaviours from a randomly selected sample of women. A detailed description of the methodology is available elsewhere ${ }^{20}$. The survey questions ask about past and present involvement in health-care systems, participation in public and food assistance programmes, food insecurity, prenatal care, breast-feeding, vitamin use, physical activity, substance use, utilisation of cancer-screening procedures, domestic violence, and demographic information. Trained interviewers conduct the interviews in English or Spanish. The questionnaire contains about 200 questions, and the English version takes about $30 \mathrm{~min}$ to administer. Data are collected monthly from January to December. The protocol pertaining to recruitment and data collection was approved by the California Health and Human Services Committee for Protection of Human Subjects.

A screened random digit dial sample is used in the CWHS. All women who are 18 years and older and live in the selected household are eligible to participate in the survey. If more than one per household is eligible, one woman is randomly selected for an interview, conducted either at that time or later by appointment. Interviewers make two additional attempts to recruit participants who refuse initially to participate. Fifteen attempts are made to contact households with busy signals, no answer or message machines. The upper-bound response rate for CWHS in 2004 was $74 \%$.

The questionnaire was developed by the California Women's Health Survey Group and staff working collaboratively with experts in women's health. Wherever possible, questions were selected from previously conducted national or statewide surveys to achieve comparability. Specific wording of the mental and physical health questions used in this study can be found in a summary report available online ${ }^{21}$.

The six food security items are a subset of the US Department of Agriculture (USDA) 18-item FSM and are recommended for use when the longer form is not feasible $^{2}$. The items were modified to refer only to the respondent and not to other adults in the household. The exact wording of the items was: (1) 'The food that I bought just didn't last, and I didn't have money to get more. Was that often, sometimes, or never true for you in the last 12 months?'; (2) 'I couldn't afford to eat balanced meals. Was that often, sometimes, or never true for you in the last 12 months?'; (3) 'In the last 12 months, did you ever cut the size of your meals or skip meals because there wasn't enough money for food? Yes or No'; (4) 'If the response is "Yes", how often did this happen? Was it almost every month, some but not every month, or only in one or two months in the last 12 months?'; (5) 'In the last 12 months, did you ever eat less than you felt you should because there wasn't enough money to buy food? Yes or No'; and (6) 'In the last 12 months, were you ever hungry but didn't eat because you couldn't afford enough food? Yes or No'. Prevalence rates from the 6-item subset can be adjusted to be comparable to those estimated by the full 18-item instrument. However, since the short form does not contain any items specifically asking about inadequate food intake (i.e. skipping meals or cutting meal size) among children, it does not measure severe levels of hunger. The appropriate scoring for the short form, based on the number of affirmative responses, is: $0-1$, food-secure; 2-4, food-insecure without hunger; 5-6, food-insecure with moderate hunger. In the logistic regression analyses, the dependent variable was coded in binary form as food-secure or food-insecure, the latter including with and without moderate hunger.

Of the 4557 interviews in the CWHS, 4037 (88.6\%) were complete. Subjects providing complete interviews 
were significantly more likely to be White, have higher incomes, less likely to be Hispanic/Latino, and less likely to be interviewed in Spanish than those with partial interviews. In the analysis, the data were weighted, based on guidance from the Survey Research Group, to reflect the age and racial/ethnic characteristics of the California population in the year $2000^{20}$.

To identify factors associated with food insecurity, bivariate analyses were carried out using chi-square tests for the categorical and $t$-tests for the continuous variables. Selection of candidate variables was generally based on the literature reviewed above. In some cases categorical variables were collapsed into binary form. For example, low education was defined as: yes, $<12$ years; no, $\geq 12$ years. We also included a self-reported item that specified whether the subject had ever been removed from her home by the state, county or court and went to live with people other than parents. The variable is considered a proxy for foster care and was included based on interest of the Department of Social Services. In the multivariate analyses, factors were tested for their relationship to food insecurity, controlling for income as a percentage of the federal poverty level. To minimise collinearity problems in the multivariate logistic regression analyses, variables were selected using stepwise procedures in three stages: (1) enter and select best demographic variables (age, education, race/ethnicity, household composition, employment status); (2) enter and select best immigrant status variables (Spanish-speaking, birthplace, proportion of life in the USA); and (3) enter and select best health correlates (general health, physical health, mental health). The final step examined the best candidate variables, significant at $P<0.05$, from all three stages. A separate analysis of covariance was carried out among women who were receiving food stamps. An additional variable considered in the stepwise selection process for this subgroup included whether or not food stamps lasted 30 days. SAS version 8.0 (1999-2001) was used in all analyses (SAS Institute). The protocol for the data analysis reported here was exempted from human subjects review by the University of California Institutional Review Board.

\section{Results}

As shown in Table 1, the prevalence of food insecurity in the general population of women was $25.7 \%$. Of these women, $17.7 \%$ were food-insecure without hunger and $8.0 \%$ were hungry. As expected, among the 225 women participating in the FSP, the prevalence of food insecurity was higher. About $71 \%$ of these women were foodinsecure and, of these, 26\% were hungry. Among FSPeligible women who had not applied for the programme, the level of food insecurity was lower among women responding that they did not need food stamps than in women giving other reasons for not applying (23.9\% vs. $66.9 \%, P<0.001)$. Although low income is a major determinant of food insecurity, almost $10 \%$ of the women with incomes of $250 \%$ of the federal poverty level or higher also reported some level of food insecurity.

\section{Bivariate analyses}

In the bivariate analyses in the general population, food insecurity was associated with several demographic, immigrant- and health-related variables (Tables 1 and 2). In addition to low income, some factors associated with greater food insecurity included the following: children in the home; female-headed household (single mother); being separated or part of an unmarried couple; pregnancy; younger age (18-24 years); having less than a 12th grade education or General Equivalency Degree; Black or Latino/Hispanic race/ethnicity; unable to work or out of work for more than a year; ever removed from one's home as a child (i.e. placed in foster care); and lack of health insurance. Immigrants reported higher levels of food insecurity than non-immigrants. Several indicators of mental, physical or emotional problems were also associated with greater food insecurity, including having a mental, physical or emotional problem that interferes with activities; having fair to poor health; being depressed or sad; and feeling overwhelmed.

Fewer of the above factors were significantly different among food-secure and food-insecure FSP recipients. However, the prevalence of food insecurity continued to vary by race/ethnicity: White (not Hispanic), 53.7\%; Black (not Hispanic), 60.8\%; Latino/Hispanic, 82.2\%; and Other, $86.5 \%(P<0.0002)$. Women who could not make food stamps last for an entire month were more food-insecure than those who could $(78.3 \%$ vs. $49.8 \%$ food-insecure, $P<0.0001)$. The prevalence of food insecurity was also higher among FSP recipients who were foreign-born (86.8\%) compared with US-born (61.7\%, $P<0.0001)$; interviewed in Spanish (87\%) rather than English $(64.5 \%$, $P<0.0006)$; and had less than 12 years of education (78.9\%) compared with more education $(66.4 \%, P<0.04)$. Pregnant FSP recipients tended to report greater levels of food insecurity (89\%) than non-pregnant recipients (69.7\%, $P<0.07)$. Other factors significantly related to greater food insecurity included feeling overwhelmed, sadness and depression, and having spent a lower proportion of one's life in the USA (data not shown).

\section{Multivariate analyses}

In the multivariate logistic regression analyses in the general population, several factors remained independently associated with the odds of being food-insecure, after controlling for income as a percentage of the federal poverty level and all variables in the model (Table 3). Factors that increased the odds of food insecurity were Latino/Hispanic race/ethnicity; Black race/ethnicity; less than a 12th grade education; being unmarried; under 55 years of age; Spanish-speaking (i.e. interviewed in Spanish); and having spent less than half of one's life in 
Table 1 Prevalence of food insecurity among California women, by selected household characteristics, 2004

\begin{tabular}{|c|c|c|c|c|c|}
\hline \multirow[b]{2}{*}{ Category } & \multirow[b]{2}{*}{ Total no. (\%) } & \multirow[b]{2}{*}{ Food-secure (\%) } & \multicolumn{3}{|c|}{ Food-insecure } \\
\hline & & & All (\%) & Without hunger (\%) & With hunger (\%) \\
\hline All & $4037(100)$ & 74.3 & 25.7 & 17.7 & 8.0 \\
\hline \multicolumn{6}{|c|}{ Household composition } \\
\hline Yes & $1897(46.8)$ & 66.8 & 33.3 & 23.7 & 9.5 \\
\hline No & $2140(53.0)$ & 81.0 & 19.0 & 12.4 & 6.6 \\
\hline \multicolumn{6}{|c|}{ With children, $6-12$ years } \\
\hline Yes & 1005 (24.9) & 63.8 & 36.2 & 25.7 & 10.5 \\
\hline No & $3030(75.1)$ & 77.8 & 22.3 & 15.1 & 7.1 \\
\hline \multicolumn{6}{|c|}{ With children, $<6$ years } \\
\hline Yes & 989 (24.5) & 64.2 & 35.8 & 25.9 & 9.9 \\
\hline No & $3045(75.5)$ & 77.6 & 22.4 & 15.1 & 7.3 \\
\hline \multicolumn{6}{|l|}{ Single mother } \\
\hline Yes & $669(16.6)$ & 52.0 & 48.0 & 33.2 & 14.8 \\
\hline No & 3367 (83.4) & 78.7 & 21.3 & 14.7 & 6.6 \\
\hline \multicolumn{6}{|l|}{ Pregnant woman } \\
\hline Yes & $125(3.1)$ & 62.9 & 37.1 & 30.1 & 7.1 \\
\hline No & $3910(96.9)$ & 74.7 & 25.3 & 17.3 & 8.0 \\
\hline \multicolumn{6}{|l|}{ Age of woman } \\
\hline $18-24$ years & $498(12.4)$ & 59.9 & 40.1 & 30.7 & 9.4 \\
\hline $25-34$ years & $829(20.5)$ & 67.7 & 32.3 & 22.9 & 9.3 \\
\hline $35-44$ years & 879 (21.8) & 75.6 & 24.4 & 17.1 & 7.3 \\
\hline $45-54$ years & 718 (17.8) & 75.3 & 24.7 & 14.4 & 10.3 \\
\hline $55-64$ years & $450(11.1)$ & 78.9 & 21.1 & 12.1 & 8.9 \\
\hline $65-98$ years & $663(16.4)$ & 87.4 & 12.6 & 9.7 & 2.9 \\
\hline \multicolumn{6}{|l|}{ Birthplace } \\
\hline United States & 2866 (71.2) & 81.0 & 19.0 & 12.3 & 6.7 \\
\hline Mexico & $540(13.4)$ & 38.4 & 61.6 & 45.2 & 16.4 \\
\hline All other & $618(15.4)$ & 74.7 & 25.3 & 18.8 & 6.5 \\
\hline \multicolumn{6}{|c|}{ Race/ethnicity of woman } \\
\hline White, not Hispanic & $2173(53.8)$ & 85.5 & 14.6 & 8.2 & 6.4 \\
\hline Black, not Hispanic & $252(6.3)$ & 63.3 & 36.7 & 24.2 & 12.5 \\
\hline Hispanic/Latino & $1055(26.1)$ & 50.6 & 49.4 & 37.3 & 12.1 \\
\hline Other, not Hispanic & $557(13.8)$ & 80.7 & 19.3 & 15.1 & 4.3 \\
\hline \multicolumn{6}{|l|}{ Ever in foster care* } \\
\hline Yes & $116(2.9)$ & 58.4 & 41.6 & 19.7 & 22.0 \\
\hline No & $3915(97.1)$ & 74.8 & 25.2 & 17.7 & 7.6 \\
\hline \multicolumn{6}{|c|}{ Household income-to-poverty ratio } \\
\hline Under 1.00 & $632(16.9)$ & 35.8 & 64.2 & 43.0 & 21.2 \\
\hline $1.00-1.29$ & $226(6.0)$ & 50.5 & 50.0 & 30.0 & 19.5 \\
\hline $1.30-1.85$ & 417 (11.2) & 61.7 & 38.3 & 26.7 & 11.6 \\
\hline $1.86-2.00$ & $68(1.8)$ & 66.5 & 33.5 & 21.3 & 12.2 \\
\hline $2.01-2.49$ & $291(7.8)$ & 75.7 & 24.3 & 17.8 & 6.5 \\
\hline $2.50+$ & 2103 (56.3) & 90.5 & 9.5 & 7.0 & 2.5 \\
\hline All $<2.00$ & & 52.8 & 47.2 & 31.9 & 15.3 \\
\hline \multicolumn{6}{|c|}{ Have health insurance } \\
\hline Yes & 3345 (82.9) & 79.4 & 20.7 & 14.3 & 6.3 \\
\hline No & $692(17.1)$ & 49.9 & 50.1 & 34.1 & 16.0 \\
\hline Have any health or & tal problem tha & nterferes with activi & & & \\
\hline Yes & $812(20.1)$ & 64.5 & 35.5 & 21.5 & 14.0 \\
\hline No & $3221(79.9)$ & 76.8 & 23.2 & 16.8 & 6.5 \\
\hline Education & & & & & \\
\hline Low (<12 years) & $590(14.6)$ & 38.2 & 61.8 & 45.4 & 16.4 \\
\hline$<9$ th grade & $291(7.2)$ & 31.2 & 68.8 & 50.3 & 18.5 \\
\hline Some high school & $299(7.4)$ & 45.0 & 55.1 & 40.6 & 14.4 \\
\hline High school/GED & 901 (22.3) & 68.0 & 32.0 & 21.6 & 10.4 \\
\hline Some technical & $24(0.6)$ & 79.9 & 20.1 & 13.8 & 6.4 \\
\hline Technical school & $53(1.3)$ & 84.8 & 15.3 & 10.2 & 5.1 \\
\hline Some college & 1076 (26.7) & 78.1 & 21.9 & 13.3 & 8.7 \\
\hline College graduate & $850(21.1)$ & 88.4 & 11.7 & 8.7 & 3.0 \\
\hline Postgraduate & $543(13.5)$ & 93.3 & 6.7 & 5.2 & 1.5 \\
\hline
\end{tabular}


Table 1. Continued

\begin{tabular}{|c|c|c|c|c|c|}
\hline \multirow[b]{2}{*}{ Category } & \multirow[b]{2}{*}{ Total no. (\%) } & \multirow[b]{2}{*}{ Food-secure (\%) } & \multicolumn{3}{|c|}{ Food-insecure } \\
\hline & & & All $(\%)$ & Without hunger (\%) & With hunger (\%) \\
\hline \multicolumn{6}{|l|}{ Marital status } \\
\hline Married & 2172 (53.9) & 80.5 & 19.5 & 14.5 & 5.0 \\
\hline Divorced & 476 (11.8) & 65.5 & 34.5 & 18.0 & 16.5 \\
\hline Widowed & $330(8.2)$ & 82.7 & 17.3 & 10.8 & 6.5 \\
\hline Separated & $123(3.1)$ & 42.0 & 58.0 & 32.0 & 25.9 \\
\hline Never married & $676(16.8)$ & 71.8 & 28.2 & 21.5 & 6.7 \\
\hline Unmarried couple & $256(6.3)$ & 48.9 & 51.0 & 37.5 & 13.6 \\
\hline \multicolumn{6}{|l|}{ Interviewed in Spanish } \\
\hline Yes & $600(14.9)$ & 34.9 & 65.1 & 48.3 & 16.9 \\
\hline No & $3437(85.1)$ & 81.2 & 28.8 & 12.4 & 6.4 \\
\hline \multicolumn{6}{|l|}{ Employment status } \\
\hline Full-time & $1306(32.4)$ & 80.0 & 20.0 & 13.8 & 6.3 \\
\hline Part-time & $528(13.1)$ & 71.1 & 28.9 & 20.7 & 8.8 \\
\hline Self-employed & $276(6.9)$ & 84.9 & 15.1 & 10.5 & 4.7 \\
\hline Out of work $>1$ year & $112(2.8)$ & 47.7 & 52.3 & 35.6 & 16.7 \\
\hline Out of work $<1$ year & $153(3.8)$ & 63.9 & 36.1 & 25.5 & 10.6 \\
\hline Homemaker & 706 (17.5) & 68.1 & 31.9 & 23.5 & 8.5 \\
\hline Student & $221(5.5)$ & 72.1 & 27.9 & 23.5 & 4.3 \\
\hline Retired & $517(12.8)$ & 90.4 & 9.6 & 7.3 & 2.2 \\
\hline Unable to work & $214(5.3)$ & 39.2 & 60.8 & 30.8 & 30.0 \\
\hline \multicolumn{6}{|c|}{ Self-reported general health } \\
\hline Good to excellent & 3334 (82.6) & 80.0 & 20.1 & 14.2 & 5.9 \\
\hline Fair to poor & $703(17.4)$ & 47.6 & 52.4 & 34.5 & 17.9 \\
\hline
\end{tabular}

GED - General Equivalency Degree.

${ }^{*}$ Asks if subject had ever been removed from her home by the state, county or court, and went to live with people other than parents.

the USA. Other significant correlates of food insecurity included sadness/depression for two or more days during the previous month; feeling overwhelmed; poor physical/ mental health interfering with activities; and general health being fair to poor. Several interactions were examined including those between being Spanish-speaking, having children at home and having low education, but none was significant.
In a separate analysis among FSP recipients only, analysis of covariance was used to identify variables that were significantly and independently related to greater food insecurity, expressed as a continuous variable (Table 4). These variables included being unable to make food stamps last for an entire month, being Spanishspeaking and feeling overwhelmed. Several interactions were examined but none was significant. The variables in

Table 2 Health-related and other variables associated with food insecurity among California women, 2004

\begin{tabular}{|c|c|c|}
\hline Variable & Food-secure & Food-insecure \\
\hline Years in the USA* & $\begin{array}{r}22.5 \pm 15.8 \\
(n=603)\end{array}$ & $\begin{array}{r}16.5 \pm 11.5 \\
(n=472)\end{array}$ \\
\hline Proportion of life in the USA $(0-1.0)$ & $\begin{array}{r}0.89 \pm 0.23 \\
(n=3054)\end{array}$ & $\begin{array}{r}0.72 \pm 0.32 \\
\quad(n=957)\end{array}$ \\
\hline Poor physical health (days) $\dagger$ & $\begin{aligned} 3.7 & \pm 7.1 \\
(n & =3057)\end{aligned}$ & $\begin{aligned} 6.6 & \pm 9.5 \\
(n & =960)\end{aligned}$ \\
\hline Poor mental health (days) $\dagger$ & $\begin{aligned} & 3.4 \pm 6.2 \\
&(n=3064)\end{aligned}$ & $\begin{array}{l}7.2 \pm 9.5 \\
(n=959)\end{array}$ \\
\hline Feeling overwhelmed ( $1=$ very often to $5=$ never) & $\begin{aligned} 4.2 & \pm 0.9 \\
(n & =3066)\end{aligned}$ & $\begin{aligned} 3.2 & \pm 1.3 \\
(n & =967)\end{aligned}$ \\
\hline Feeling sad/depressed (days)† & $\begin{aligned} 3.5 & \pm 5.8 \\
(n & =3065)\end{aligned}$ & $\begin{aligned} 8.1 & \pm 9.1 \\
(n & =967)\end{aligned}$ \\
\hline Poor mental or physical health interfered with activities (days)† & $\begin{aligned} 1.9 & \pm 5.2 \\
(n & =3065)\end{aligned}$ & $\begin{aligned} 4.9 & \pm 8.2 \\
(n & =965)\end{aligned}$ \\
\hline Age (years) & $\begin{aligned} 46.7 & \pm 16.4 \\
(n & =3069)\end{aligned}$ & $\begin{array}{r}39.3 \pm 14.8 \\
(n=968)\end{array}$ \\
\hline
\end{tabular}

Data are presented as mean \pm standard deviation.

All differences significant at $P<0.0001$ ( $t$-test).

${ }^{*}$ Among foreign-born women only.

†Each of these questions was coded as the number of days in the past month that the health problem occurred. For example, poor physical health was captured as: 'Now thinking about your physical health, which includes physical illness and injury, for how many days during the past 30 days was your physical health not good? Response: __ Number of days'. 
Table 3 Variables independently associated with food insecurity in California women, $2004(n=4037)$

\begin{tabular}{|c|c|}
\hline Independent variable & $\begin{array}{c}\text { Adjusted odds ratio* } \\
\text { (95\% confidence interval) }\end{array}$ \\
\hline \multicolumn{2}{|l|}{ Race/ethnicity } \\
\hline Latino/Hispanic & $1.45(1.07,1.96)$ \\
\hline African American & $1.76(1.21,2.58)$ \\
\hline Asian/Other & $0.88(0.63,1.22)$ \\
\hline White & 1.00 \\
\hline \multicolumn{2}{|l|}{ Education } \\
\hline Less than 12 years & $2.03(1.52,2.72)$ \\
\hline 12 years/GED or more & 1.00 \\
\hline \multicolumn{2}{|l|}{ Marital status } \\
\hline Married & $0.64(0.52,0.80)$ \\
\hline Not married & 1.00 \\
\hline \multicolumn{2}{|l|}{ Age } \\
\hline Under 55 years & $1.59(1.23,2.07)$ \\
\hline 55 years and older & 1.00 \\
\hline \multicolumn{2}{|c|}{ Spanish-speaking (interviewed in Spanish) } \\
\hline Yes & $1.91(1.27,2.87)$ \\
\hline No & 1.00 \\
\hline \multicolumn{2}{|c|}{ Less than half of life spent in the USA } \\
\hline Yes & $1.56(1.14,2.15)$ \\
\hline No & 1.00 \\
\hline \multicolumn{2}{|l|}{ Sadness/depression } \\
\hline 2 or more days of month & $1.61(1.28,2.02)$ \\
\hline None/less than 2 days & 1.00 \\
\hline \multicolumn{2}{|c|}{ Feel overwhelmed in past 30 days } \\
\hline Very often/often/sometimes & $3.10(2.49,3.85)$ \\
\hline Rarely/never & 1.00 \\
\hline \multicolumn{2}{|c|}{ Physical/mental health interfered with normal activities in past 30 days } \\
\hline Yes (1 or more days) & $1.81(1.45,2.27)$ \\
\hline No (0 days) & 1.00 \\
\hline \multicolumn{2}{|l|}{ General health } \\
\hline Fair/poor & $1.49(1.14,1.95)$ \\
\hline Excellent/very good/good & 1.00 \\
\hline
\end{tabular}

GED - General Equivalency Degree.

${ }^{*}$ Adjusted for income as \% of federal poverty ratio (multivariate logistic regression analysis).

the final model, which controlled for pregnancy status, education and income, accounted for about $20 \%$ of the variance in food insecurity.

\section{Discussion}

In this population of California women, the correlates of food insecurity are similar to those identified in other regional and national studies ${ }^{3}$. Low income is one of the strongest predictors, but other factors independently associated with food insecurity include race/ethnicity, marital status, less than a 12th grade education and immigrant status. Several indicators of poor physical, mental and emotional health are also associated with food insecurity. This study, like most other studies that have reported associations between food insecurity and physical/mental health, is cross-sectional in design ${ }^{11,12,14,15}$. One panel study also reported a significant association between changes in household food insufficiency and changes in mental health status among welfare recipients ${ }^{13}$. Nevertheless, whether food insecurity is a cause or effect of deterioration in mental health remains in question.

The unique contribution of our study is the examination of food insecurity, as experienced by women, in a large population-based, ethnically diverse sample. Whereas other studies ask about hunger among all adults in the household, the CWHS directs the questions to the individual female respondents. Our estimate of food insecurity among California women $(25.7 \%)$ is more than twice as high as the figure (12.4\%) reported by the Current Population Survey (CPS) for California households from 2002 to $2004^{3}$. The prevalence of food insecurity in this study is also higher than that previously reported in the California Health Interview Survey (CHIS) ${ }^{6}$. Conducted in 2003, the CHIS estimate of food insecurity prevalence among households with incomes less than $200 \%$ of the federal poverty level is $33.9 \%$, compared with the estimate of $47.2 \%$ for the same income level in 2004. Although estimates from the CWHS and the CHIS are from two different years, the most likely reason for the difference lies in the methodology and specifically the wording of the questions in the surveys. In the CWHS, the six items (as detailed under methods) refer to food insecurity as it directly affects the individual woman responding to the survey. In the CHIS, the questions are worded to capture food insecurity among all adult household members. Since women tend to compromise their own food intakes to spare other family members ${ }^{19}$, the CWHS might be expected to yield a higher estimate than the CHIS and the CPS. Although not strictly comparable, reports from the CPS indicate that single women (living alone or with children) report higher levels of food insecurity than do single men (living alone or with children $)^{3}$.

Table 4 Variables independently associated with food insecurity* in low-income California women who are food stamp recipients, 2004

\begin{tabular}{|c|c|c|c|}
\hline Independent variable & Regression coefficient & Standard error & $P$-value \\
\hline Food stamps last 30 days $(1=$ no, $0=$ yes $)$ & 1.66811 & 0.30043 & $<0.0001$ \\
\hline Born in Mexico or Central America $(1=$ yes, $0=$ no) & 0.74462 & 0.31155 & $<0.0177$ \\
\hline Felt overwhelmed in past 30 days (range $1-5$, where $1=$ never and $5=$ very often) & -0.30030 & 0.09183 & $<0.0001$ \\
\hline Pregnancy status $(1=$ yes, $0=$ no) & 0.64954 & 0.44400 & NS \\
\hline Maternal education (range $1-8$ ) & 0.09839 & 0.07520 & NS \\
\hline Income, as $\%$ of federal poverty ratio & -0.08379 & 0.08197 & NS \\
\hline
\end{tabular}

NS - not significant.

${ }^{*}$ Food insecurity is the dependent variable (range $0-6$, where $0=$ least and $6=$ most food-insecure); $n=225$, adjusted $R^{2}=0.19$. 
Interestingly, our estimate of the prevalence of food insecurity among Latino/Hispanic women is almost identical ( $49.4 \%$ vs. $50.4 \%$ ) to that reported in another recent survey, using the 10-item FSM, conducted in California in 2001 among more than 500 low-income Latina mothers with young children ${ }^{22}$. Although being interviewed in Spanish was strongly associated with greater food insecurity, other variables related to immigrant status (e.g. born in Mexico or Latin America) were similarly related. Moreover, in the multivariate analyses, the association was independent of income, household size and the woman's educational level. More analyses are needed to determine why the immigrant population is at particularly high risk of food insecurity. One possibility is that in households with recent immigrants, women attempt to spare both their children and husbands from hunger by reducing their own food intakes first, whereas in other types of households all adults share the burden more equally ${ }^{23}$. Another possibility is that these households experience more confusion regarding food selection in American stores, compared with English-speaking, non-immigrant women. In focus groups with Mexican immigrants, this problem was mentioned as contributing to food insecurity, along with seasonal unemployment, lack of transportation and high cost of food. Immigrant families may, in effect, also be larger than reported to social services if some income is sent home as remittances or households temporarily shelter new arrivals from their countries of origin. Finally, immigrant women may not know how to access food assistance programmes or realise that their US-born children are potentially eligible for these programmes ${ }^{24}$. They may also be afraid of applying for food assistance if they are undocumented immigrants. An important caveat to mention about the dataset is that interviews were conducted only in English and Spanish, and therefore immigrants who speak other languages are underrepresented in the survey. Thus, other non-Englishspeaking immigrant groups may also be at increased risk of food insecurity.

The findings confirm that the FSP attracts and serves a relatively needy population, yet food insecurity persists among many recipients. An important and possibly modifiable factor contributing to food insecurity among FSP recipients is the inability to make food stamps last for an entire month. In Connecticut, inability to make food stamps last for a month was similarly related to food insecurity, independent of total food stamp allotment and maternal formal education ${ }^{10}$. Interventions teaching life skills, including shopping, menu planning and food preparation skills, may help increase food security in FSP recipients. A better system of client referrals to the community nutrition education programmes, such as the Food Stamp Nutrition Education and the Expanded Food and Nutrition Education Program, may be needed to provide this education. The federal Special Supplemental
Nutrition Program for Women, Infants, and Children (WIC), which provides both food assistance and nutrition education, is another important way to improve food security in low-income women. A study reported that pregnant WIC participants with higher level educational levels were more likely to become food-secure, as a result of receiving WIC services, than less-educated participants $^{25}$. To improve food insecurity among low-income women with less education and/or limited English proficiency, more nutrition education contacts and greater coordination among USDA programmes may be needed.

Our findings also indicate that food-insecure women report more mental, physical and emotional problems than those who are food-secure. A cross-sectional study cannot determine the direction of causation. However, it is clear that these issues are present and need to be addressed to make public health and economic interventions more effective in improving food security.

In summary, the present study has identified important factors that social services and public health agencies should consider in developing outreach and educational interventions to improve food security.

\section{Acknowledgements}

Sources of funding: Data for these analyses were provided by the California Women's Health Survey (CWHS) Group. The CWHS is coordinated by the California Department of Health Services in collaboration with the California Department of Mental Health, the California Department of Alcohol and Drug Programs, the Californian Medical Review Inc., the Department of Social Services, and the Public Health Institute. Questionnaire development and funding for the survey were provided by the collaborating programmes. Analyses, findings and conclusions described in this report are not necessarily endorsed by the CWHS Group.

Conflict of interest declaration: None to declare.

Authorship responsibilities: L.K. did the literature review and multivariate analysis, and wrote the first draft; S.D. did the bivariate analysis and wrote a preliminary report; N.B. participated in design of the CWHS questions, framed the question for this study, and provided input on the draft.

\section{References}

1 Anderson SA. Core indicators of nutritional state for difficultto-sample populations. Journal of Nutrition 1990; 121(Suppl. 11): 1559-600.

2 Radimer KL. Measurement of household food insecurity in the USA and other industrialized countries. Public Health Nutrition 2002; 5(6A): 859-64.

3 Nord M, Andrews M, Carlson S. Household Food Security in the United States, 2004 [online]. Food Assistance and Nutrition Research Report No. ERR11. Washington, DC: Food and Rural Economics Division, Economic Research Service, US Department of Agriculture, October 2005. 
Available at http://www.ers.usda.gov/publications/err11/. Accessed 24 February 2006.

4 Rose D. Economic determinants and dietary consequences of food insecurity in the United States. Journal of Nutrition 1999; 129(2 Suppl.): 517S-20S.

5 Holben DH, McClincy MC, Holcomb JP Jr, Dean KL, Walker CE. Food security status of households in Appalachian Ohio with children in Head Start. Journal of American Dietetic Association 2004; 104(2): 238-41.

6 Harrison GG, Manolo-LeClair G, Ramirez A, Chia YJ, Kurata J, McGarvey N, et al. More than 2.3 million Californians now Food Insecure - One in Three Low-income, An Increase in just Two Years. Los Angeles, CA: UCLA Center for Health Policy Research, June 2005.

7 Meyers A, Cutts D, Frank DA, Levenson S, Skalicky A, Heeren T, et al. Subsidized housing and children's nutritional status: data from a multisite surveillance study. Archives of Pediatrics \& Adolescent Medicine 2005; 159(6): 551-6.

8 Quandt SA, Arcury TA, Early J, Tapia J, Davis JD. Household food security among migrant and seasonal Latino farmworkers in North Carolina. Public Health Reports 2004; 119(6): 568-75.

9 Olson CM, Anderson K, Kiss E, Lawrence FC, Seiling SB. Factors protecting against and contributing to food insecurity among rural families. Family Economics and Nutrition Review 2004; 16(1): 12-20.

10 Perez-Escamilla R, Ferris AM, Drake L, Haldeman L, Peranick J, Campbell M, et al. Food stamps are associated with food security and dietary intake of inner-city preschoolers from Hartford, Connecticut. Journal of Nutrition 2000; 130(11): 2711-7.

11 Stuff JE, Casey PH, Szeto KL, Gossett JM, Robbins JM, Simpson PM, et al. Household food insecurity is associated with adult health status. Journal of Nutrition 2004; 134(9): $2330-5$.

12 Casey P, Goolsby S, Berkowitz C, Frank D, Cook J, Cutts D, et al. Maternal depression, changing public assistance, food security, and child health status. Pediatrics 2004; 113(2): 298-304.

13 Heflin CM, Siefert K, Williams DR. Food insufficiency and women's mental health: findings from a 3-year panel of welfare recipients. Social Science \& Medicine 2005; 61(9): 1971-82.

14 Vozoris NT, Tarasuk VS. Household food insufficiency is associated with poorer health. Journal of Nutrition 2003; 133(1): $120-6$.
15 Pheley AM, Holben DH, Graham AS, Simpson C. Food security and perceptions of health status: a preliminary study in rural Appalachia. Journal of Rural Health 2002; 18(3): $447-54$.

16 Winicki J, Jollife D, Gundersen C. How do Food Assistance Programs Improve the Well-being of Low-income Families? [online]. Food Assistance and Nutrition Research Report No. 26-9. Washington, DC: Economic Research Service, US Department of Agriculture, 2002. Available at http://www. ers.usda.gov/publications/fanrr26/fanrr26-9/. Accessed 27 February 2006.

17 California Immigrant Welfare Collaborative. Immigrants in California [online], July 2002. Available at http://www.ppic. org/content/pubs/jtf/JTF_ImmigrantsJTF.pdf. Accessed 17 August 2006.

18 Kasper J, Gupta SK, Tran P, Cook JT, Meyers AF. Hunger in legal immigrants in California, Texas, and Illinois. American Journal of Public Health 2000; 90(10): 1629-33.

19 Olson CM. Food insecurity in women. A recipe for unhealthy trade-offs. Topics in Clinical Nutrition 2005; 20(4): 321-8.

20 Survey Research Group. California Women's Health Survey SAS Dataset Documentation and Technical Report. Sacramento, CA: California Department of Health Services, 2005.

21 Office of Women's Health. Women's Health: Findings from the California Women's Health Survey 1997-2000 [online], May 2006. Available at http://www.dhs.ca.gov/director/ owh/owh_main/cwhs/wmns_hlth_survey/survey.htm. Accessed 17 August 2006.

22 Kaiser LL, Townsend MS, Melgar-Quiñonez HR, Fujii ML, Crawford PC. Choice of instrument influences relationship between food insecurity and obesity in Latino women. American Journal of Clinical Nutrition 2004; 80(5): 1372-8.

23 Melgar-Quiñonez HR, Martin AC, Metz D, Olivares A, Kaiser LL. Inseguridad alimentaria en Latinos de California: observaciones de grupos focales. Salud Pública de México 2003; 45(3): 198-205.

24 Geltman PL, Meyers AF. Immigration legal status and use of public programs and prenatal care. Journal of Immigrant Health 1999; 1(2): 91-7.

25 Herman DD, Harrison GG, Afifi A, Jenks E. Effect of the WIC program on food security status of pregnant, first-time participants. Family Economics and Nutrition Review 2004; 16(1): 21-30. 